\title{
A STUDY FOR SUSTAINABLE DEVELOPMENT IN OPTOELECTRONICS INDUSTRY USING MULTIPLE CRITERIA DECISION MAKING METHODS
}

\author{
Chun-Chu LIU', An-Chin CHENG ${ }^{\mathrm{b}}$, Shih-Hui CHEN ${ }^{\mathrm{a}}$ \\ ${ }^{a}$ Chang Jung Christian University, No. 1 Changda Rd., Gueiren District, Tainan City 71101, Taiwan \\ ${ }^{b}$ Chaoyang University of Technology, Taichung, Taiwan
}

Received 20 November 2012; accepted 18 January 2014

\begin{abstract}
This study assessed the operational efficiency of the optoelectronics industry in the Southern Taiwan Science Park (STSP) between 2007 and 2011 by using multiple criteria decision making methods (data envelopment analysis, Malmquist productivity index and Bootstrap). The data analysis showed that during the study period, meaning that the operational efficiency gap among manufacturers in STSP is widening. Among these manufacturers, eight manufacturers exhibited constant returns to scale, which was more than a half of the overall decision making unit (DMU), indicating that the operational scale of these manufacturers was nearing the optimal scale. Based on Malmquist productivity index (MPI) analysis, the factors that affect the operational efficiencies of optoelectronics manufacturers' were as follow: operational cost, the number of employees, and the amount of fixed assets. The development should be focused on increasing technological efficiency and technological change in the future. Finally, based on Bootstrap, the results showed that the focus should be on the production technology while improving productive efficiency to ensure sustainable development of the entire domestic optoelectronics industry in the future.
\end{abstract}

Keywords: sustainable development, operational efficiency, data envelopment analysis, Malmquist productivity index, Bootstrap.

JEL Classification: O47, L80, C61.

\section{Introduction}

Over the past 50 years of industrialisation, regional imbalances in the growth of Taiwan's industries, population distribution, and the distribution of national income have intensified the polarisation between the central and peripheral regions. Therefore, promoting regionally balanced development has always been an important policy objective of the government of Taiwan. The Southern Taiwan Science Park (STSP) is one of the achievements

Corresponding author Chun-Chu Liu

E-mail: lcc@mail.cjcu.edu.tw 
of this policy and was designed to generate the economic growth, thereby decreasing the wealth and urban-rural gaps.

The STSP grew from the original 2 manufacturers in 1998 to 177 manufacturers in June 2012 June. The STSP contains various industries, including Optoelectronics, Precision Machinery, Biotechnology, Integrated Circuits, Telecommunications, and Computer \& Peripherals. Therefore, the establishment of the STSP is crucial to the sustainable development of the domestic economy as well as industrial transformation and advancement; furthermore, it could be the foundation for future growth. By June 2012, there were a total of 177 manufacturers in STSP, 49 (27.68\%) of which were optoelectronics firms, forming an optoelectronics industry cluster that encompassed the entire optoelectronics production process, including key components in the upstream, panels in the mid-stream, liquid-crystal display televisions (LCD-TV) in the downstream. STSP plays an important role in Taiwan's growth in the global flat panel display market, especially with the respective entries of internationally renowned manufacturers such as JNC Corporation (Japan), Sumika (Japan), Corning (U.S.A) and 3M (P.R China), as well as the continuing expansion of major flat panel manufacturer Chimei Innolux.

Niven (2002) stated that the performance measurement methods were widely adopted in many industries. There are several Data Envelopment Analysis (DEA) applications, such as Technology (Chang, Chen 2008), health care (Wilson et al. 2012; Assaf, Matawie 2010), education (Kong, Fu 2012; Tommaso 2011), manufacturing (Fukuyama, Mirdehghan 2012; Sun 2002), retailing (Akanksha, Sanjiv 2010; Lu, Hung 2011), banking (Paradi, Zhu 2013), etc. The previous studies mostly focused on assessing efficiency and providing suggestions for improvements but did not involve extensive economic analysis. In order to fill this gap, the purpose of this paper is to provide valuable insights into how to generate a comprehensive performance measurement model for the Optoelectronics industry. This study is based on the optoelectronics industry cluster as categorised by the STSP Administration Division's official webpage, including liquid crystal/alignment film, polariser, colour filter, glass substrate, cold-cathode fluorescent lamp CCFL, light emitting displays (LED), LCD panels, processing equipment, masks, backlight modules, LCM modules, driver IC, and LCD-TV and other manufacturers, to measure STSP's operational efficiency. We calculated the operational efficiencies of the optoelectronics manufacturers using Data Envelopment Analysis (DEA), the Malmquist Productivity Index (MPI), and Bootstrap to provide a reference for relevant organisations in making their regional and national optoelectronics industry development policies.

Therefore, the purpose of this study can be summarised as follows:

1. To assess STSP's optoelectronics industry's operational efficiency and changes in its efficiency using DEA and MPI.

2. To establish standard deviations in efficiency scores using Bootstrap, with the goal of obtaining more practical efficiency scores.

3. To provide suggestions for relevant organisations in formulating policies for the regional and national development of the optoelectronics industry based on the estimation model and results of analyses using DEA, MPI, and Bootstrap. 
This paper is divided into four parts: 1) introduction, which explains the background, motive, and objectives of this study; 2) research methodology, which explains the DEA, MPI, and Bootstrap analysis methods used in this study; 3 ) empirical analysis, which explains the results; 4) conclusions.

\section{Methodology}

\subsection{Data Envelopment Analysis (DEA)}

DEA is a method of measuring efficiency which originates from Farrell's (1957) proposal of employing non-parametric method to evaluate efficiency. According to Farrell's method of using multiple inputs to measure efficiency, a linear combination is conducted on each subject's output and input factors. The ratio of the two linear combinations is used to represent the subject's efficiency. Subsequently, the relative position of the empirical observation with respect to this boundary is used to calculate the technical efficiency, also known as productive efficiency, or technical and scale efficiency. Factor price is then included to obtain price efficiency, also known as the allocative efficiency. The product of price efficiency and allocative efficiency will yield overall efficiency, or total economic efficiency.

The method that Farrell proposed was later expanded and modified by Charnes, Cooper, and Rhodes (CCR 1978). After mathematical modification, the ratio of the linear combinations of each output and input factor are used to represent DMU efficiency; hence, an optimal selection can be made under optimal circumstances for each assessment factor and the efficiency score must be between 0 and 1 . Therefore, under the CCR modification, after fractional programming is converted to linear programming, multiple inputs and outputs are accounted for, and DMU productive efficiency can be measured under CRS. The mathematical model of CCR is as follows:

$$
\begin{gathered}
\text { Max } h_{k}=\frac{\sum_{r=1}^{s} U_{r} Y_{r k}}{\sum_{i=1}^{m} V_{i} X_{i k}} ; \\
\text { st. } \frac{\sum_{r=1}^{s} U_{r} Y_{r j}}{\sum_{i=1}^{m} V_{i} X_{i j}} \leq 1 ; \\
U_{r}, V_{i} \geq \varepsilon \geq 0 ; i=1,2, \cdots, m ; r=1,2, \cdots, s ; j=1,2, \cdots, n,
\end{gathered}
$$

where, $Y_{r j}$ is the r-th output value of the $\mathrm{j}$-th DMU; $X_{i j}$ is the $\mathrm{i}$-th input value of the $\mathrm{j}$-th DMU; $U_{r}$ is the r-th weighted output value of the $\mathrm{j}$-th DMU; $V_{i}$ is the $\mathrm{i}$-th weighted input value of the $\mathrm{j}$-th DMU; $h_{k}$ is the efficiency score of the k-th DMU.

Banker, Charnes and Cooper (BCC 1984) modified the CCR Model to create the BCC Model. The BCC model can be used to measure pure technical efficiency and scale effi- 
ciency under variable returns to scale. The mathematical model of BCC is as follows:

$$
\begin{aligned}
\operatorname{Max} h_{k}=\frac{\sum_{r=1}^{s} U_{r} Y_{r j}-V_{o}}{\sum_{i=1}^{m} V_{i} X_{i j}} ; \\
\text { st. } \frac{\sum_{r=1}^{s} U_{r} Y_{r j}-V_{0}}{\sum_{i=1}^{m} V_{i} X_{i j}} \leq 1 ;
\end{aligned}
$$

$U_{r}, V_{i} \geq \varepsilon>0 ; i=1,2, \cdots, m ; r=1,2, \cdots, s ; j=1,2, \cdots, n ; V_{0}$ has no upper or lower limits.

Based on the CCR Model and BCC Model introduces an additional variable, $V_{0}$. $V_{0}$ represents the pattern in returns to scale; $V_{0}<0$ represents increasing returns to scale; $V_{0}=0$ represents constant returns to scale; and $V_{0}>0$ represents decreasing returns to scale. So CCR models are a specific type of BCC models (Toloo et al. 2009).

\subsection{Malmquist Productivity Index (MPI)}

The MPI uses panel data on empirical input and output observation values to measure changes in total factor productivity across periods. MPI was first proposed by Caves et al. (1982), but named after Malmquist (1953), who first used the distance function. Caves et al. (1982) combined Malmquist's theory with a distance function from Shephard (1970) and proposed using MPI to measure productivity. The Malmquist index has seen many applications and extensions (Chen 2003; Pastor, Lovell 2005; Shestalova 2003). MPI is defined as the distance ratio for two arbitrary periods, $s$ and $t$, under the same technology; the mathematical formula is shown in equation 3 and 4 .

$$
\begin{aligned}
& \text { Period } s \quad M^{t}\left(x^{t}, y^{t}, x^{s}, y^{s}\right)=\frac{d^{s}\left(x^{t}, y^{t}\right)}{d^{s}\left(x^{s}, y^{s}\right)} \\
& \text { Period } t \quad M^{s}\left(x^{t}, y^{t}, x^{s}, y^{s}\right)=\frac{d^{t}\left(x^{t}, y^{t}\right)}{d^{t}\left(x^{s}, y^{s}\right)} .
\end{aligned}
$$

Färe et al. (1994) proposed a modified model based on the model developed by Caves et al. (1982) and explained that MPI can be obtained by multiplying technical efficiency change (TEC) under fixed scale technique change (TC) under fixed scale; i.e., MPI = TEC $\times$ TC; the mathematical formulas are shown in equations 5,6 , and 7 :

$$
\begin{aligned}
\text { MPI: }\left(x^{t}, y^{t}, x^{s}, y^{s} \mid C R S\right) & =\left[\frac{d^{s}\left(x^{t}, y^{t} \mid C R S\right)}{d^{s}\left(x^{s}, y^{s} \mid C R S\right)} \frac{d^{t}\left(x^{t}, y^{t} \mid C R S\right)}{d^{t}\left(x^{s}, y^{s} \mid C R S\right)}\right]^{\frac{1}{2}} ; \\
\text { TEC } & =\frac{d^{t}\left(x^{t}, y^{t} \mid C R S\right)}{d^{s}\left(x^{s}, y^{s} \mid C R S\right)} ;
\end{aligned}
$$




$$
\mathrm{TC}=\left[\frac{d^{s}\left(x^{s}, y^{s} \mid C R S\right)}{d^{t}\left(x^{s}, y^{s} \mid C R S\right)} \frac{d^{S}\left(x^{t}, y^{t} \mid C R S\right)}{d^{t}\left(x^{t}, y^{t} \mid C R S\right)}\right]^{\frac{1}{2}} .
$$

When MPI $>1$, productivity improved from period $s$ to period $t$; when MPI $<1$, productivity decreased. When TEC $>1$, efficiency has improved; if TEC $<1$, efficiency has deteriorated. When TC $>1$, technology has advanced; if $\mathrm{TC}<1$, technology has declined.

Although MPI targets CRS for analysis, TEC can be further decomposition the pure technical efficiency change (PTEC) and scale efficiency change (SEC) caused by the difference between CRS and VRS; i.e., TEC $=$ PTEC $\times$ SEC. We can be understood the impact of changes in returns to scale on efficiency. The mathematical models are shown in equation 8 and 9:

$$
\begin{gathered}
\text { PTEC }=\frac{d^{t}\left(x^{t}, y^{t} \mid V R S\right)}{d^{s}\left(x^{s}, y^{s} \mid V R S\right)} \\
\mathrm{SEC}=\left[\frac{d^{t}\left(x^{t}, y^{t} \mid C R S\right)}{d^{s}\left(x^{s}, y^{s} \mid C R S\right)} \frac{d^{s}\left(x^{s}, y^{s} \mid V R S\right)}{d^{t}\left(x^{t}, y^{t} \mid V R S\right)}\right] .
\end{gathered}
$$

PTEC is the ratio of pure technical efficiency scores under VRS in two periods. If PTEC $>1$, pure technical efficiency is improved; if PTEC $<1$, pure technical efficiency is reduced. If SEC $>1$, period $t$, compared to period $s$, is approaching CRS, meaning that the model is approaching the optimum in the long-run; if $\mathrm{SEC}<1$, this the model diverged from the long-run optimal model.

\subsection{Bootstrap}

Bootstrap, a self-sampling method, is a nonparametric statistical inference technique proposed by Efron (1979). The application of the procedure is based on the assumption that the limited data can be expressed in the form of statistical sample which possesses the property of representativeness (Vaidogas, Juocevicius 2007). Based on the smooth technique proposed by Simar and Wilson (1999), by assuming a limited number $(\mathrm{N})$ of samples, assigning equally distributed probabilities to each observation value $(1 / \mathrm{N})$, and then randomly drawing samples from the pool repeatedly, a continuous probability distribution can be obtained. The more times re-sampling is performed, the smaller the standard deviation; therefore, one can effectively avoid the problem of large standard deviations due to a small data pool. Efron and Tibshirani's (1993) demonstrated that after performing 1000 re-samplings, the distribution obtained from self-sampling will accurately approach the actual sample distribution. Therefore, with this method, only limited historical data are needed for sampling to model the characteristics of the parameter in question. Because the sample distribution can be simulated, the sample can be evaluated and assessed. 


\section{Empirical analysis}

This study used the DEA operating procedures proposed by Golany and Roll (1989). After confirming the DMU range and variable selection, we introduced MPI and used Bootstrap to modify the DEA and MPI model, with the aim of increasing the rigor of the study and strengthening the explanatory power of the research findings.

\subsection{DMU selection}

A total of 32 manufacturers were selected, including LCD and alignment film, polariser, colour filter, glass substrates, CCFL, LED, condenser, LCD panel, process equipment, mask, backlight module, LCM module, driver IC, and LCD-TV. Of the 32 manufacturers, 17 are subsidiaries of major international manufacturers located in STSP. Considering that we were not obtained complete financial statements, these 17 manufacturers were excluded from our study according to DEA selection criteria. Therefore, a total of 15 domestic manufacturers were chosen as the DMU for this study, as shown in Table 1.

Table 1. 15 DMUs

\begin{tabular}{cll}
\hline No. & \multicolumn{1}{c}{ DMU } & \multicolumn{1}{c}{ Optoelectronics cluster } \\
\hline 1 & Optimax Technology Corporation & Polariser \\
\hline 2 & HannsTouch Solution & Colour Filter Film \\
\hline 3 & Epistar & LED \\
\hline 4 & Formosa Epitaxy & LED \\
\hline 5 & Genesis Photonics & LED \\
\hline 6 & Chimei Innolux Corporation & LCD panel, LCM module, LCD-TV \\
\hline 7 & HannStar & LCD panel, LCM module \\
\hline 8 & Contrel & Processing equipment \\
\hline 9 & Tongtai & Processing equipment \\
\hline 10 & Marketech International Corporation (MIC) & Processing equipment \\
\hline 11 & UTechzone & Processing equipment \\
\hline 12 & Gallant Precision Machining (GPM) & Processing equipment \\
\hline 13 & Coretronic & Backlight module \\
\hline 14 & Kenmos & Backlight module \\
\hline 15 & ChipMOS & Driver IC \\
\hline
\end{tabular}

\subsection{Selection of input and output variables}

From the Taiwan Economics Journal (TEJ) database, we obtained sources for input and output variables and performed our preliminary variable selection. Subsequently, assess the relevance of each input and output variable, we demonstrated that when the number of inputs increases, the number of outputs also increases, which adheres to the isotonicity of DEA. Among the output variables used in this study, pre-tax net profit had a negative value due to the scarcity of manufacturers' annual reports that were available; therefore, in 
this study we added the minimum value of the data points (i.e., HannStar 2005) to each DMU's pre-tax net profit, to ensure that all DMU's pre-tax net profits were positive, which met the translational invariance requirement of DEA.

Golany and Roll (1989) establish a rule of thumb that the number of units should be at least twice the number of inputs and outputs considered. Bowlin (1998) mentions that the number of units should be three times the number of inputs and outputs variables. Dyson et al. (2001) recommend a total of two times the product of the number of input and output variables. Eventually, we selected a total of 5 variables including 3 input variables and 2 output variables. The explanation and Correlation analysis of each input and output variable are shown in Table 2 and Table 3, respectively.

Table 2. Input and output variables

\begin{tabular}{lll}
\hline \multicolumn{1}{c}{ Variables } & \multicolumn{1}{c}{ Unit } & \multicolumn{1}{c}{ Operational definition } \\
\hline Fixed asset (I1) & NT\$1000 & $\begin{array}{l}\text { Include land, building, construction, plant \& equipment, } \\
\text { etc. }\end{array}$ \\
\hline Operation cost (I2) & NT\$1000 & Total of development, management \& promotional Cost \\
\hline No. of employees (I3) & person & All direct and indirect production staff in this year \\
\hline Net operation income (O1) & NT\$1000 & Income on sales minus returned product and discounts \\
\hline Pre-tax net profit (O2) & NT\$1000 & $\begin{array}{l}\text { Operation Income plus additional income minus } \\
\text { additional Cost }\end{array}$ \\
\hline
\end{tabular}

Table 3. Input and output correlation analysis

\begin{tabular}{lcc}
\hline \multicolumn{1}{c}{ Variables } & Net Operation Income (O1) & Pre-tax Net Profit (O2) \\
\hline Fixed asset (I1) & 0.961 & 0.712 \\
\hline Operation cost (I2) & 0.984 & 0.728 \\
\hline Number of employees (I3) & 0.926 & 0.681 \\
\hline
\end{tabular}

\subsection{Efficiency analysis}

In this study, we had performed an efficiency analysis, targeting STSP manufacturers for CCR and BCC operational efficiency assessment. Among these, total technical efficiency under CRS was obtained using the CCR model, while pure technical efficiency under VRS was obtained using the BCC model. The scale efficiency was then obtained by dividing total technical efficiency by pure technical efficiency to further evaluate the efficiency of the DMU.

The overall efficiency categorisation in this study is shown in Table 4. The CCR model assumes that all DMU operate under CRS, and the reason for productivity inefficiency is not entirely a result of technical inefficiency; it is possible that part of the cause is the manufacturers' scale inefficiency. Therefore, from the BCC Model, the scale return conditions can be further understood, and we may be able to distinguish whether overall technical inefficiency is due to pure technical inefficiency or scale inefficiency and provide improved advice and recommendations. As shown in Table 4, from an overview of the STSP manufacturers, the average pure technical efficiency was 0.9112 , higher than the 
scale efficiency of 0.8979 , but the difference was small. Six manufacturers had lower pure technical efficiency than scale efficiency, while six other manufacturers had lower scale efficiency, demonstrating that for manufacturers with operational inefficiency, technical factors and scale factors are equally important. These results showed that technical inefficiency and scale inefficiency were both factors that lowered operational efficiency among STSP manufacturers.

For three of the manufacturers, HannsTouch Solution, Formosa Epitaxy, and MIC, inefficiencies were mostly a result of pure technical efficiency being lower than scale efficiency, demonstrating that pure technical inefficiency was the reason for total technical inefficiency among these manufacturers. Five manufacturers, Epistar, Chimei Innolux, Contrel, Tongtai and ChipMOS, exhibited weak scale efficiency, which caused the deterioration in total technical efficiency, suggesting that these manufacturers need to improve their operational scales. For three manufactures, Optimax, HannStar, and GPM, both pure technical inefficiency and scale inefficiency contributed to the total technical inefficiency during the sample period. Furthermore, four manufacturers, Genesis Photonics, UTechzone, Coretronic, and Kenmos, all had a total technical efficiency of 1 . Therefore, based on our research findings, we observe that STSP manufacturers had more significant problems with scale factors than technical factors, demonstrating that manufacturers had poor performance in management and operational scale. This problem should be taken seriously and addressed by the management. Manufacturers with lower pure technical efficiencies had deficiencies in introducing and accumulating technologies and need improvement.

Table 4. Average total technical efficiency, pure technical efficiency, scale efficiency between 2007-2011

\begin{tabular}{lccc}
\hline DMU & $\begin{array}{c}\text { Total technical } \\
\text { efficiency }\end{array}$ & $\begin{array}{c}\text { Pure technical } \\
\text { efficiency }\end{array}$ & $\begin{array}{c}\text { Scale } \\
\text { efficiency }\end{array}$ \\
\hline Optimax & 0.6045 & $0.7623 \#$ & 0.8264 \\
\hline HannsTouch Solution & 0.7390 & $0.7565 \#$ & 0.9738 \\
\hline Epistar & 0.4533 & 0.7512 & $0.6071 \#$ \\
\hline Formosa Epitaxy & 0.6100 & $0.6752 \#$ & 0.9174 \\
\hline Genesis Photonics & 1.0000 & 1.0000 & 1.0000 \\
\hline Chimei Innolux & 0.8147 & 1.0000 & $0.8147 \#$ \\
\hline HannStar & 0.8942 & $0.9379 \#$ & 0.9518 \\
\hline Contrel & 0.7538 & 0.9631 & $0.7884 \#$ \\
\hline Tongtai & 0.8323 & 1.0000 & $0.8323 \#$ \\
\hline MIC & 0.9551 & $0.9607 \#$ & 0.9938 \\
\hline UTechzone & 1.0000 & 1.0000 & 1.0000 \\
\hline GPM & 0.8495 & $0.8824 \#$ & 0.9601 \\
\hline Coretronic & 1.0000 & 1.0000 & 1.0000 \\
\hline Kenmos & 1.0000 & 1.0000 & 1.0000 \\
\hline ChipMOS & 0.7809 & 0.9780 & $0.8020 \#$ \\
\hline Average & 0.8192 & 0.9112 & $0.8979 \#$ \\
\hline Note: & &
\end{tabular}

Note: \# denotes important factors that lead to average inefficiency among manufactures in the 20072011. 
Following Norman and Stoker (1991) and based on the efficiency scores, we divided the DMU into four categories: highly efficient companies, borderline efficient companies, borderline inefficient companies, and obviously inefficient companies.

As shown in Table 5, in 2007, Genesis Photonics, MIC, and Coretronic are highly efficient companies; HannsTouch Solution, Contrel, UTechzone, GPM, and Kenmos are borderline efficient companies; Chimei Innolux and HannStar are borderline inefficient companies; and Optimax, Epistar, Formosa Epitaxy, Tongtai, and ChipMOS are obviously inefficient companies. In 2005, Genesis Photonics, HannStar, MIC, Coretronic, and Kenmos are highly efficient companies; UTechzone and GPM are borderline efficient companies; the rest are all obviously inefficient companies. In 2007 and in recent years, Genesis Photonics, HannStar, UTechzone, Coretronic, and Kenmos are highly efficient companies; ChipMOS and Tongtai are borderline efficient companies; and Optimax, HannsTouch Solution, Epistar, Formosa Epitaxy, Chimei Innolux, Contrel, MIC, and GPM are obviously inefficient companies.

Over the five-year research period, the number of both highly efficient companies and obviously inefficient companies increased, and the difference between the manufacturers with comparatively better operational efficiencies and the manufacturers with comparatively worse operational efficiencies became increasingly significant. Genesis Photonics, MIC, and Coretronic are the three best performers, as they are highly efficient companies in most years. HannStar, Kenmos, and UTechzone had better growth rates compared to other manufacturers, and their operational efficiencies improved over the years, from borderline efficient or borderline inefficient in 2007 to highly efficient in 2011.

Table 5. Overall efficiency

\begin{tabular}{|c|c|c|c|}
\hline $\mathrm{Category}^{\text {Time }}$ & 2007 & 2009 & 2011 \\
\hline $\begin{array}{l}\text { Highly } \\
\text { Efficient } \\
\text { Companies }\end{array}$ & $\begin{array}{l}\text { Genesis Photonics, } \\
\text { MIC, Coretronic }\end{array}$ & $\begin{array}{l}\text { Genesis Photonics, } \\
\text { HannStar, MIC, Coretronic, } \\
\text { Kenmos }\end{array}$ & $\begin{array}{l}\text { New Century, HannStar, } \\
\text { UTechzone, Coretronic, } \\
\text { Kenmos }\end{array}$ \\
\hline $\begin{array}{l}\text { Borderline } \\
\text { Efficient } \\
\text { Companies } \\
\end{array}$ & $\begin{array}{l}\text { HannsTouch Solution, } \\
\text { Contrel, UTechzone, } \\
\text { GPM, Kenmos }\end{array}$ & UTechzone, GPM & ChipMOS \\
\hline $\begin{array}{l}\text { Borderline } \\
\text { Inefficient } \\
\text { Companies }\end{array}$ & $\begin{array}{l}\text { Chimei Innolux, } \\
\text { HannStar }\end{array}$ & - & Tongtai \\
\hline $\begin{array}{l}\text { Obviously } \\
\text { Inefficient } \\
\text { Companies }\end{array}$ & $\begin{array}{l}\text { Optimax, Epistar, } \\
\text { Formosa Epitaxy, } \\
\text { Tongtai, ChipMOS }\end{array}$ & $\begin{array}{l}\text { Optimax, HannsTouch } \\
\text { Solution, Epistar, Formosa } \\
\text { Epitaxy, Chimei Innolux, } \\
\text { Contrel, Tongtai, ChipMOS }\end{array}$ & $\begin{array}{l}\text { Optimax, HannsTouch } \\
\text { Solution, Epistar, Formosa } \\
\text { Epitaxy, Chimei Innolux, } \\
\text { Contrel, MIC, CPM } \\
\end{array}$ \\
\hline
\end{tabular}

\subsection{Return to scale analysis}

In the BCC model, $V_{0}$ represents the indicator for returns to scale; $V_{0}<0$ means increasing returns to scale; $V_{0}=0$ means constant returns to scale; and $V_{0}>0$ means decreasing returns to scale. CRS means that the assessed company has the optimal production scale 
and has achieved efficiency. When returns to scale increase, the company can appropriately expand its operational scale to increase operational efficiency; when returns to scale decrease, production has surpassed the optimal scale, and the company should appropriately decrease in scale to increase production efficiency.

Table 6 reports the overall production returns to scale among STSP manufacturers' operational efficiencies during the 2007-2011 period. There were approximately eight manufacturers that exhibited CRS each year, which is over half of the manufacturers, suggesting that STSP manufactures performed well in terms of scale adjustments. Moreover, as shown in Table 7, among the manufacturers, Genesis Photonics, MIC, UTechzone, Coretronic, and Kenmos had the best performance and maintained optimal production models over the five years covered by this study. HannsTouch Solution and Formosa Epitaxy exhibited increasing returns to scale, meaning that they should expand the scale of their operations via resource integration and increase inputs to reach the optimal production scale. However, Epistar, Chimei Innolux, Tongtai, and ChipMOS exhibited decreasing returns to scale for four years or more out of the five-year research period; consequently, they should consider decreasing manufacturing scale to increase productive efficiency. The remaining manufacturers generally exhibited increasing or fixed returns to scale over the five years covered by the study and might also need to adjust their scales accordingly.

Table 6. 2007-2011 Returns to scale analysis statistics (unit: number of DMU)

\begin{tabular}{|c|c|c|c|c|c|}
\hline $\begin{array}{l}\text { RTS } \\
\text { Time }\end{array}$ & 2007 & 2008 & 2009 & 2010 & 2011 \\
\hline IRS & - & - & 1 & 1 & 3 \\
\hline CRS & 8 & 7 & 9 & 6 & 9 \\
\hline DRS & 7 & 8 & 5 & 8 & 3 \\
\hline
\end{tabular}

Note: IRS = increasing returns to scale, CRS = constant returns to scale, DRS = decreasing returns to scale.

Table 7. 2007-2011 DMU returns to scale analysis

\begin{tabular}{|c|c|c|c|c|c|c|c|c|}
\hline $\mathrm{DMU}_{\mathrm{DM}}$ Time RTS & 2007 & 2008 & 2009 & 2010 & 2011 & IRS & CSR & DRS \\
\hline Optimax & DRS & DRS & CRS & DRS & CRS & - & 2 & 3 \\
\hline HannsTouch Solution & CRS & CRS & IRS & CRS & IRS & 2 & 3 & - \\
\hline Epistar & DRS & DRS & DRS & DRS & DRS & - & - & 5 \\
\hline Formosa Epitaxy & DRS & DRS & CRS & IRS & IRS & 2 & 1 & 2 \\
\hline Genesis Photonics & CRS & CRS & CRS & CRS & CSR & - & 5 & - \\
\hline Chimei Innolux & DRS & DRS & DRS & DRS & DRS & - & - & 5 \\
\hline HannStar & DRS & DRS & CRS & DRS & CRS & - & 2 & 3 \\
\hline Contrel & CRS & DRS & DRS & DRS & CRS & - & 2 & 3 \\
\hline Tongtai & DRS & DRS & DRS & DRS & DRS & - & - & 5 \\
\hline $\mathrm{MIC}$ & CRS & CRS & CRS & CRS & CRS & - & 5 & - \\
\hline UTechzone & CRS & CRS & CRS & CRS & CRS & - & 5 & - \\
\hline GPM & CRS & CRS & CRS & DRS & IRD & 1 & 3 & 1 \\
\hline Coretronic & CRS & CRS & CRS & CRS & CRS & - & 5 & - \\
\hline Kenmos & CRS & CRS & CRS & CRS & CRS & - & 5 & - \\
\hline ChipMOS & DRS & DRS & DRS & DRS & CRS & - & 1 & 4 \\
\hline
\end{tabular}




\subsection{Variable difference analysis}

The CCR Model was used to calculate variable differences. In addition, as the units for each input and output variable vary, we used ratios (in percentage terms) to measure the difference between optimal and actual values and determined the magnitude of improvement for each manufacturer. Table 8 shows the overall excessive investments for the manufacturers each year. STSP manufacturers' fixed assets are the source of excess investment, and the amount of excess investment was approximately $14.19 \%$. Judging from the average operational costs and the number of staff, the excess magnitude was approximately $1-3 \%$; this indicates that the scale adjustments were good. From overall output, after adjusting for on input, pre-tax net profit increased $25.5 \%$, thereby reaching optimal output and allowing total technical efficiency to achieve the optimal efficiency score.

Table 8. 2007-2011 Input output variable difference analysis (unit: \%)

\begin{tabular}{|c|c|c|c|c|c|c|}
\hline $\begin{array}{ll}\text { Variables } & \text { Time }\end{array}$ & 2007 & 2008 & 2009 & 2010 & 2011 & Average \\
\hline Fixed asset & 21.55 & 19.07 & 5.40 & 23.17 & 1.77 & 14.19 \\
\hline Operational cost & 1.76 & 0.35 & 0.00 & 2.05 & 2.74 & 1.38 \\
\hline Staff number & 5.10 & 0.00 & 0.71 & 4.40 & 2.88 & 2.62 \\
\hline Operational income & 0.00 & 0.00 & 0.00 & 0.00 & 0.00 & 0.00 \\
\hline Pre-tax net profit & 29.65 & 24.61 & 8.94 & 56.77 & 7.51 & 25.50 \\
\hline
\end{tabular}

\subsection{Sensitivity analysis}

This study conducted a sensitivity analysis, focusing on observing and exploring efficiency changes after eliminating each input and output variable. We aimed to understand the extent of the impact of each variable on the manufacturers' operational efficiency to determine the specific input and output factors with the greatest influence. Table 9 shows the efficiency scores and magnitudes of change before and after excluding the input and output values. The results showed that the three input variables and two output variables are all causes of the original declining operational efficiency, proving that these five performance indicators have positive influences on STSP manufacturers' operational efficiency.

Specifically, based on overall average values in the 2007-2011 period, the efficiency scores exhibited the greatest variation before and after eliminating operational income. Originally, overall efficiency was 0.9182 , and after elimination the efficiency score was 0.4056 , with a change rate as high as $50.33 \%$, demonstrating that this variable has the greatest influence on STSP manufacturers. Pre-tax net profit was the variable with the second largest magnitude of change, with a post-elimination value of 0.6474 and a change rate of $20.94 \%$, showing that earnings, profit, and loss are still the most important variables that affect companies and manufacturers. All of the input variables had some influence. The variables, in order of importance, were the following: operational cost, staff number, and fixed assets; the change rates for the variables were $11.83 \%, 8.46 \%$, and $6.83 \%$, respectively. 
Table 9. 2007-2011 Input output sensitivity analysis

\begin{tabular}{lcccccc}
\hline Variables & \multirow{2}{*}{2007} & 2008 & 2009 & 2010 & 2011 & Average \\
\hline Original total technical efficiency & 0.9169 & 0.8193 & 0.7634 & 0.7772 & 0.8190 & 0.8192 \\
\hline Exclude fixed asset & 0.8503 & 0.7861 & 0.7192 & 0.7247 & 0.7347 & 0.7630 \\
\hline Change rate (\%) & 7.26 & 4.05 & 5.79 & 6.76 & 10.29 & 6.83 \\
\hline Exclude operational cost & 0.7933 & 0.7139 & 0.7019 & 0.6865 & 0.7120 & 0.7215 \\
\hline Change rate (\%) & 13.48 & 12.86 & 8.06 & 11.67 & 13.06 & 11.83 \\
\hline Exclude staff number & 0.8733 & 0.7450 & 0.6608 & 0.6967 & 0.7806 & 0.7513 \\
\hline Change rate (\%) & 4.76 & 9.07 & 13.44 & 10.36 & 4.69 & 8.46 \\
\hline Exclude operational income & 0.4006 & 0.3994 & 0.3769 & 0.3972 & 0.4541 & 0.4056 \\
\hline Change rate (\%) & 56.31 & 51.25 & 50.63 & 48.89 & 44.55 & 50.33 \\
\hline Exclude pre-tax net profit & 0.7224 & 0.6589 & 0.6204 & 0.6073 & 0.6281 & 0.6474 \\
\hline Change rate (\%) & 21.21 & 19.58 & 18.73 & 21.86 & 23.31 & 20.94 \\
\hline
\end{tabular}

\subsection{Productivity change analysis}

This study perform the MPI analysis, and the results are shown in Table 10. According to this analysis, a total of six DMUs increased total factor productivity, among which HannStar and ChipMOS's growth rates were led by technique changes and TECs; Coretronic and Kenmos's growth rates were mostly due to technique changes; Optimax and Chimei Innolux, while experiencing deteriorating TECs, still had strong technique changes, leading to overall growth in total factor productivity. Our study revealed that these six DMUs had the common characteristic that technique changes exhibit competitive advantages, which are the main causes of overall advances in total factor productivity.

However, HannsTouch Solution, Epistar, Formosa Epitaxy, Genesis Photonics, Contrel, Tongtai, MIC, UTechzone, and GMP all had MPI values below 1, meaning that after calculating the geometric average over the five-year period, they showed deteriorating trends. Epistar, Formosa Epitaxy, Contrel, MIC, and GMP showed deterioration in both TECs and technique changes. Genesis Photonics and UTechzone's deteriorations occurred mostly in technique changes. HannsTouch Solution, although experiencing improvements in technique changes still had overall deterioration due to strong deterioration in TEC. Tongtai showed growth in TECs, but its poor performance in technique changes caused an overall deterioration. The results demonstrate that other than HannsTouch Solution, the other DMUs all showed deterioration in technique changes, which, under deteriorating or constant TECs, causes poor performance in total factor productivity.

Based on the DMU analysis, we examined all of manufacturers' performances on the basis of the average value of efficiency change during the entire study period. The results show that the average total factor productivity of 0.946 is deteriorating, with only six manufacturers that improved. Meanwhile, TEC, as the major cause for the decline, resulted in the deterioration of eight manufacturers, approximately $53.33 \%$ of the total (in PTEC, seven manufacturers showed deterioration; in Scale efficiency changes, five manufactur- 
ers showed deterioration). In other words, TECs and technique changes had geometric averages of 0.966 and 0.979 , respectively; the product of these two values results in a total factor productivity that is less than 1 , thus showing a negative trend. Therefore, the overall industry still needs to improve productive efficiency and strengthen production technology to enhance the competitiveness of the overall STSP optoelectronics industry.

Table 10. 2007-2011 Efficiency score changes

\begin{tabular}{lccccc}
\hline \multicolumn{1}{c}{ DMU } & EFFCH & TECHCH & PECH & SECH & TFPCH \\
\hline 1. Optimax & 0.978 & 1.089 & 0.913 & 1.071 & 1.065 \\
\hline 2. HannsTouch Solution & 0.897 & 1.091 & 0.917 & 0.978 & 0.978 \\
\hline 3. Epistar & 0.921 & 0.992 & 0.914 & 1.008 & 0.914 \\
\hline 4. Formosa Epitaxy & 0.926 & 0.907 & 0.901 & 1.027 & 0.839 \\
\hline 5. Genesis Photonics & 1.000 & 0.767 & 1.000 & 1.000 & 0.767 \\
\hline 6. Chimei Innolux & 0.976 & 1.189 & 1.000 & 0.976 & 1.161 \\
\hline 7. HannStar & 1.019 & 1.182 & 1.000 & 1.019 & 1.205 \\
\hline 8. Contrel & 0.935 & 0.831 & 0.950 & 0.984 & 0.777 \\
\hline 9. Tongtai & 1.030 & 0.955 & 1.000 & 1.030 & 0.984 \\
\hline 10. MIC & 0.971 & 0.976 & 0.976 & 0.995 & 0.948 \\
\hline 11. UTechzone & 1.000 & 0.764 & 1.000 & 1.000 & 0.764 \\
\hline 12. GPM & 0.834 & 0.836 & 0.843 & 0.989 & 0.697 \\
\hline 13. Coretronic & 1.000 & 1.116 & 1.000 & 1.000 & 1.116 \\
\hline 14. Kenmos & 1.000 & 1.028 & 1.000 & 1.000 & 1.028 \\
\hline 15. ChipMOS & 1.031 & 1.111 & 1.027 & 1.003 & 1.145 \\
\hline Average & 0.966 & 0.979 & 0.961 & 1.005 & 0.946 \\
\hline
\end{tabular}

\subsection{MPI and bootstrap analysis}

From the MPI analysis, the information on each category of efficiency change of each DMU over the entire study period can be acquired, but due to the lack of statistical support in the application process, it is often difficult to present accurate results for the efficiency scores. To address this issue, our study used the MPI combined with Bootstrapping to solve the problem of a lack of statistical support. Via statistical assessment and statistical inference (interval estimation), we determined whether the index shows significant change. Compared to the point estimation provided by the MPI, the method used in our study enables us to obtain more accurate statistical estimates. The results of this analysis are shown in the following tables.

\subsubsection{Total factor productivity with bootstrap}

Table 11 shows that, using the MPI analysis on the original average values of total factor productivity change over the research period, six DMUs showed improving trends, nine DMUs showed deteriorating trends, and no DMU remained in the same condition. However, after the application of the Bootstrap procedure, the number of DMU that showed sig- 
nificant changes in total factor productivity decreased considerably. Among these DMUs, four showed significant improvement, and five DMUs showed significant deterioration.

The statistical inference can also be explained by the confidence interval. Under Percentile and BCa validations, Optimax, Chimei Innolux, Coretronic, and ChipMOS show a growth trend and their confidence intervals had upper and lower bounds greater than 1 . Therefore, after statistical assessment, we inferred that these four manufacturers had significant improvements in total factor productivity change. Formosa Epitaxy, Genesis Photonics, Contrel, MIC, and UTechzone all showed deteriorating trends, and their confidence intervals had upper and lower bounds below 1. Therefore, after statistical assessment, we inferred that these five manufacturers had significant deteriorations in total factor productivity change, while the remaining manufacturers showed no significant changes in total factor productivity. The main cause for significant changes in total factor productivity and different categories of efficiency changes are explored in greater detail below.

Table 11. Total factor productivity with bootstrap

\begin{tabular}{lccccc}
\hline \multirow{2}{*}{ DMU } & \multirow{2}{*}{ Original } & \multicolumn{2}{c}{ Percentile } & \multicolumn{2}{c}{ BCa } \\
\cline { 3 - 6 } & & lower & upper & lower & upper \\
\hline 1. Optimax & $1.065 \#$ & 0.986 & 1.183 & 1.006 & 1.233 \\
\hline 2. HannsTouch Solution & 0.978 & 0.698 & 1.305 & 0.646 & 1.292 \\
\hline 3. Epistar & 0.914 & 0.838 & 1.016 & 0.845 & 1.034 \\
\hline 4. Formosa Epitaxy & $0.839 \#$ & 0.700 & 0.951 & 0.688 & 0.951 \\
\hline 5. Genesis Photonics & $0.767 \#$ & 0.637 & 0.927 & 0.649 & 0.964 \\
\hline 6. Chimei Innolux & $1.161 \#$ & 1.028 & 1.378 & 1.052 & 1.403 \\
\hline 7. HannStar & 1.205 & 0.921 & 1.591 & 0.965 & 1.661 \\
\hline 8. Contrel & $0.777 \#$ & 0.616 & 0.987 & 0.643 & 1.013 \\
\hline 9. Tongtai & 0.984 & 0.875 & 1.100 & 0.875 & 1.103 \\
\hline 10. MIC & $0.948 \#$ & 0.898 & 0.992 & 0.898 & 0.992 \\
\hline 11. UTechzone & $0.764 \#$ & 0.648 & 0.907 & 0.648 & 0.939 \\
\hline 12. GPM & 0.697 & 0.478 & 1.051 & 0.541 & 1.108 \\
\hline 13. Coretronic & $1.116 \#$ & 1.006 & 1.237 & 1.017 & 1.237 \\
\hline 14. Kenmos & 1.028 & 0.827 & 1.282 & 0.840 & 1.326 \\
\hline 15. ChipMOS & $1.145 \#$ & 1.020 & 1.415 & 1.027 & 1.538 \\
\hline
\end{tabular}

Note: \# indicates that there is significant change in total factor productivity.

\subsubsection{Technique change with bootstrap}

Table 12 demonstrates that over the research period, the analysis of the original average values of technique change exhibited an improving trend in seven DMUs and a deteriorating trend in eight DMUs, with no DMU showing a constant trend. However, after applying the Bootstrap procedure, manufacturers with significant improvements were limited to four DMUs: HannsTouch Solution, Chimei Innolux, HannStar, and Coretronic; manufacturers that showed significant deterioration were limited to three DMUs: Genesis Photonics, Contrel, and UTechzone; the remaining DMUs showed no significant changes. 
Table 12. Technical change with bootstrap

\begin{tabular}{lccccc}
\hline \multirow{2}{*}{ DMU } & \multirow{2}{*}{ Original } & \multicolumn{2}{c}{ Percentile } & \multicolumn{2}{c}{ BCa } \\
\cline { 3 - 6 } & & lower & upper & lower & upper \\
\hline 1. Optimax & 1.089 & 0.959 & 1.242 & 0.978 & 1.262 \\
\hline 2. HannsTouch Solution & $1.091 \#$ & 1.042 & 1.137 & 1.042 & 1.137 \\
\hline 3. Epistar & 0.992 & 0.927 & 1.052 & 0.927 & 1.059 \\
\hline 4. Formosa Epitaxy & 0.907 & 0.754 & 1.035 & 0.749 & 1.035 \\
\hline 5. Genesis Photonics & $0.767 \#$ & 0.625 & 0.927 & 0.649 & 0.964 \\
\hline 6. Chimei Innolux & $1.189 \#$ & 1.101 & 1.283 & 1.105 & 1.290 \\
\hline 7. HannStar & $1.182 \#$ & 1.112 & 1.264 & 1.134 & 1.287 \\
\hline 8. Contrel & $0.831 \#$ & 0.746 & 0.925 & 0.746 & 0.925 \\
\hline 9. Tongtai & 0.955 & 0.861 & 1.046 & 0.847 & 1.035 \\
\hline 10. MIC & 0.976 & 0.902 & 1.062 & 0.905 & 1.079 \\
\hline 11. UTechzone & $0.764 \#$ & 0.648 & 0.929 & 0.648 & 0.940 \\
\hline 12. GPM & 0.836 & 0.638 & 1.051 & 0.638 & 1.051 \\
\hline 13. Coretronic & $1.116 \#$ & 0.989 & 1.223 & 1.017 & 1.223 \\
\hline 14. Kenmos & 1.028 & 0.814 & 1.282 & 0.840 & 1.326 \\
\hline 15. ChipMOS & 1.111 & 0.895 & 1.401 & 0.915 & 1.420 \\
\hline
\end{tabular}

Note: \# denotes significant changes in technique changes.

These statistical inferences can also be explained by the confidence interval. Under Percentile and BCa validations, HannsTouch Solution, Chimei Innolux, HannStar, and Coretronic exhibited growth trends and their confidence intervals had upper and lower bounds greater than 1. Therefore, after the statistical assessment, we inferred that these four manufacturers had significant improvement in technical changes. Genesis Photonics, Contrel, MIC, and UTechzone all exhibited deteriorating trends and their confidence intervals had upper and lower bounds of less than 1. Therefore, after statistical assessment, we inferred that these three manufacturers had significant deterioration in technical change, while the remaining manufacturers showed no significant changes.

Based on the results, Chimei Innolux and Coretronic had outstanding performance in technique changes, which caused a significant improvement in their total factor productivity changes. Optimax and ChipMOS did not have obvious improvements in technical change, but they showed growth in their geometric averages and annual growth in TECs, which lead to a significant total factor productivity improvement trend. Genesis Photonics, Contrel, and UTechzone showed deteriorating technique change, leading to significant deterioration in total factor productivity change.

\subsubsection{TEC with bootstrap}

Table 13 shows that over the research period, the analysis of the original average values of TEC revealed an improvement trend for three DMUs, no change for four DMUs, and deteriorating trends for eight DMUs. However, after introducing Bootstrap, the results were noticeably different from those with MPI analysis alone. The results demonstrated that none 
of the firms included in the study showed significant growth or deterioration. HannsTouch Solution and HannStar, however, showed a significant growth in technique changes and no deterioration in TECs, although the firms performed poorly, leading to no improvement in total factor productivity. However, Formosa Epitaxy and MIC, due to deterioration in both technique change and TEC, had significant deteriorating trends in total factor productivity change. Technical efficiency can be deconstructed into pure technical efficiency and scale efficiency. We then further explore the DMU changes with Bootstrapping below.

Table 13. TEC with Bootstrap

\begin{tabular}{llllll}
\hline \multirow{2}{*}{ DMU } & \multirow{2}{*}{ Original } & \multicolumn{2}{c}{ Percentile } & \multicolumn{2}{c}{ BCa } \\
\cline { 2 - 6 } 1. Optimax & & lower & upper & lower & upper \\
\hline 2. HannsTouch Solution & 0.978 & 0.803 & 1.256 & 0.845 & 1.372 \\
\hline 3. Epistar & 0.921 & 0.815 & 1.045 & 0.815 & 1.045 \\
\hline 4. Formosa Epitaxy & 0.926 & 0.736 & 1.236 & 0.781 & 1.276 \\
\hline 5. Genesis Photonics & 1.000 & 1.000 & 1.000 & 1.000 & 1.000 \\
\hline 6. Chemei Innolux & 0.976 & 0.906 & 1.087 & 0.919 & 1.144 \\
\hline 7. HannStar & 1.019 & 0.794 & 1.400 & 0.848 & 1.564 \\
\hline 8. Contrel & 0.935 & 0.728 & 1.350 & 0.767 & 1.389 \\
\hline 9. Tongtai & 1.030 & 0.920 & 1.161 & 0.928 & 1.183 \\
\hline 10. MIC & 0.971 & 0.915 & 1.004 & 0.915 & 1.004 \\
\hline 11. UTechzone & 1.000 & 1.000 & 1.000 & 1.000 & 1.000 \\
\hline 12. GPM & 0.834 & 0.968 & 1.000 & 0.731 & 1.000 \\
\hline 13. Coretronic & 1.000 & 1.000 & 1.000 & 1.000 & 1.000 \\
\hline 14. Kenmos & 1.000 & 1.000 & 1.000 & 1.000 & 1.000 \\
\hline 15. ChipMOS & 1.031 & 0.746 & 1.439 & 0.855 & 1.524 \\
\hline
\end{tabular}

\subsubsection{PTEC with bootstrap}

From Table 14, it can be seen that, over the research period, the analysis of the original average value of PTEC showed that one DMU exhibited an improving trend, seven DMUs exhibited a constant trend, and seven DMUs exhibited deteriorating trends. After introducing bootstrap, the results matched completely with the MPI in growth trends; i.e., ChipMOS showed significant improvement, and the rest showed no significant changes. This statistical inference can also be supported using confidence intervals. Under Percentile and BCa validation, ChipMOS showed growth and both the upper and lower bound values of its confidence interval were strictly greater than 1 . Therefore, via statistical assessment, we concluded that ChipMOS had significant improvement in PTEC, while the rest of the DMUs show no significant changes. 
Table 14. PTEC with bootstrap

\begin{tabular}{llllll}
\hline \multirow{2}{*}{ DMU } & Original & \multicolumn{2}{c}{ Percentile } & \multicolumn{2}{c}{ BCa } \\
\cline { 2 - 5 } & & lower & upper & lower & upper \\
\hline 1. Optimax & 0.913 & 0.701 & 1.207 & 0.652 & 1.146 \\
\hline 2. HannsTouch Solution & 0.917 & 0.642 & 1.230 & 0.602 & 1.230 \\
\hline 3. Epistar & 0.914 & 0.774 & 1.057 & 0.774 & 1.057 \\
\hline 4. Formosa Epitaxy & 0.901 & 0.695 & 1.200 & 0.721 & 1.268 \\
\hline 5. Genesis Photonics & 1.000 & 1.000 & 1.000 & 1.000 & 1.000 \\
\hline 6. Chimei Innolux & 1.000 & 1.000 & 1.000 & 1.000 & 1.000 \\
\hline 7. HannStar & 1.000 & 0.767 & 1.338 & 0.845 & 1.338 \\
\hline 8. Contrel & 0.950 & 0.861 & 1.000 & 0.908 & 1.000 \\
\hline 9. Tongtai & 1.000 & 1.000 & 1.000 & 1.000 & 1.000 \\
\hline 10. MIC & 0.976 & 0.923 & 1.008 & 0.923 & 1.008 \\
\hline 11. UTechzone & 1.000 & 1.000 & 1.000 & 1.000 & 1.000 \\
\hline 12. GPM & 0.843 & 0.667 & 1.000 & 0.667 & 1.000 \\
\hline 13. Coretronic & 1.000 & 1.000 & 1.000 & 1.000 & 1.000 \\
\hline 14. Kenmos & 1.000 & 1.000 & 1.000 & 1.000 & 1.000 \\
\hline 15. ChipMOS & $1.027 \#$ & 1.002 & 1.104 & 1.002 & 1.104 \\
\hline
\end{tabular}

Note: \# denotes significant change in PTEC.

\subsubsection{Scale efficiency change with bootstrap}

As in Table 15, the analysis of original data of scale efficiency change over the study period showed that six DMUs exhibited returns to scale trend, four DMUs exhibited constant trends, and five DMUs exhibited non-optimal production model trends.

Table 15. Scale efficiency change with Bootstrap

\begin{tabular}{lccccc}
\hline \multirow{2}{*}{ DMU } & \multirow{2}{*}{ Original } & \multicolumn{2}{c}{ Percentile } & \multicolumn{2}{c}{ BCa } \\
\cline { 2 - 6 } & & lower & upper & lower & upper \\
\hline 1. Optimax & 1.071 & 0.827 & 1.501 & 0.886 & 1.696 \\
\hline 2. HannsTouch Solution & $0.978 \#$ & 0.959 & 0.999 & 0.959 & 0.999 \\
\hline 3. Epistar & 1.008 & 0.826 & 1.210 & 0.786 & 1.210 \\
\hline 4. Formosa Epitaxy & 1.027 & 0.906 & 1.215 & 0.932 & 1.296 \\
\hline 5. Genesis Photonics & 1.000 & 1.000 & 1.000 & 1.000 & 1.000 \\
\hline 6. Chimei Innolux & 0.976 & 0.906 & 1.099 & 0.919 & 1.144 \\
\hline 7. HannStar & 1.019 & 0.948 & 1.098 & 0.948 & 1.098 \\
\hline 8. Contrel & 0.984 & 0.728 & 1.350 & 0.758 & 1.446 \\
\hline 9. Tongtai & 1.030 & 0.920 & 1.161 & 0.920 & 1.183 \\
\hline 10. MIC & 0.995 & 0.990 & 1.000 & 0.990 & 1.000 \\
\hline 11. UTechzone & 1.000 & 1.000 & 1.000 & 1.000 & 1.000 \\
\hline 12. GPM & 0.989 & 0.882 & 1.103 & 0.916 & 1.103 \\
\hline 13. Coretronic & 1.000 & 1.000 & 1.000 & 1.000 & 1.000 \\
\hline 14. Kenmos & 1.000 & 1.000 & 1.000 & 1.000 & 1.000 \\
\hline 15. ChipMOS & 1.003 & 0.692 & 1.480 & 0.775 & 1.524 \\
\hline
\end{tabular}

Note: \# denotes a significant change in scale efficiency change. 
However, after introducing Bootstrap, only HannsTouch Solution showed a significant trend of diverting from return to scale. We can further explain our statistical inference with a confidence interval. Under Percentile and BCa validation, only HannsTouch Solution showed the trend of not reaching an optimal production scale, as its confidence interval had upper and lower bound values that are strictly less than 1 . Therefore, via statistical assessment, we inferred that HannsTouch Solution had diverted from the optimal productive scale in its scale efficiency while the rest of the DMUs showed no significant trend in production scale.

Based on the above efficiency changes combined with Bootstrap, as shown in Table 16, our research demonstrated that, via statistical assessment, we clearly detected each efficiency change, whether growth or deterioration. There were many changes in DMUs, indicating DEA's shortcomings in this application. Therefore, if DEA can be combined with statistics for validation, the measurement results will be more convincing.

Table 16. Bootstrap and original data comparison

\begin{tabular}{lccc}
\hline \multicolumn{1}{c}{ Evaluation Item } & Original & Percentile & BCa \\
\hline Total factor productivity changes & - & - & - \\
\hline Growth & 6 & 3 & 4 \\
\hline Deterioration & 9 & 5 & 4 \\
\hline Technique change & - & - & - \\
\hline Growth & 7 & 3 & 4 \\
\hline Deterioration & 8 & 3 & 3 \\
\hline TEC & - & - & - \\
\hline Growth & 3 & - & - \\
\hline Deterioration & 8 & - & - \\
\hline PTEC & - & - & - \\
\hline Growth & 1 & 1 & - \\
\hline Deterioration & 7 & - & 1 \\
\hline Scale efficiency changes & - & - & - \\
\hline Growth & 6 & - & - \\
\hline Deterioration & 5 & 1 & - \\
\hline
\end{tabular}

Note: - denotes that there is no significant change.

\section{Conclusions}

This study attempted to employ DEA, MPI, and Bootstrap to explore the competitiveness and performance efficiency of STSP manufacturers during the 2007-2011. By analysing the results, we hope to obtain information on each manufacturer's strengths and weaknesses and their resource allocations, providing inefficient manufacturers with directions for improvement and magnitude levels to increase the companies' competitive advantages by using conclusions from this study. 


\section{Efficiency analysis}

Based on the overall efficiency average, Genesis Photonics, UTechzone, Coretronic, and Kenmos are the best performing manufacturers. Furthermore, these companies are more frequently used as references by other firms. For instance, Genesis Photonics, Coretronic, and Kenmos have been categorised as higly efficient companies, and other companies all had room for efficiency improvements. During the five-year research period, we observed that the number of highly efficient companies and the number of obviously inefficient companies increased, which shows that the polarisation among STSP companies in efficiency performance is increasing.

The STSP manufacturers had an average pure technical efficiency of 0.9112 , higher than the 0.8979 for scale efficiency, but not significantly different, showing that for inefficiently operated companies, technical and scale factors are equally important. Among STSP manufacturers during the 2007-2011, in terms of overall productive returns to scale, approximately eight companies showed CRS, which is more than half of the companies, meaning that STSP's overall adjustment condition is good.

\section{Variable difference analysis}

STSP manufacturers' fixed assets are the sources of over-investment. Excess investment was approximately $14.19 \%$. Judging from the overall average operation costs and staff numbers, the excess amount was approximately $1-3 \%$ and the adjustment condition was satisfactory. From the overall output perspective, based on adjusted input, pre-tax net profit increased by $24.4 \%$, thereby achieving optimal output and allowing total technical efficiency to reach the optimal efficiency score.

\section{Sensitivity analysis}

The five selected performance indicators all caused the original efficiency scores to decrease, meaning that they had positive impacts on STSP companies in terms of operational efficiency. Judging from the overall average, operational income caused the greatest change in efficiency scores after its exclusion, from an original overall efficiency of 0.8192 to an efficiency of 0.4056 after its exclusion; the change was as high as $50.33 \%$. Pre-tax net profit also had a high change rate of $20.94 \%$ before and after its exclusion, demonstrating that earnings, profits, and losses are still the primary variables that affect companies and manufacturers. With respect to input, all variables had a certain amount of influence, in order of importance, they are as follows: operational cost, staff size, and fixed assets.

\section{MPI}

Optimax, Chimei Innolux, HannStar, Coretronic, Kenmos, and ChipMOS (a total of six DMUs) had optimal total factor productivity change. All of them showed improvement in technique change, meaning that they have competitive advantages, particularly HannStar and ChipMOS, both of which exhibited the best TEC and had growth trends. The product of the two factors allows these two companies to have even greater competitiveness. However, Coretronic, Kenmos, Optimax, and Chimei Innolux showed constant levels or dete- 
riorations in this respect; therefore, their technical efficiency does not produce as much of a competitive advantage. Conversely, nine DMUs, HannsTouch Solution, Epistar, Formosa Epitaxy, Genesis Photonics, Contrel, Tongtai, MIC, UTechzone, and GPM, all exhibited poor performance in total factor productivity. The main reasons are poor performance in technical efficiency (with the exception of Tongtai) and technique change (HannsTouch Solution).

Overall, $20 \%$ of the companies performed satisfactorily in TEC, and $26.67 \%$ maintained constant performance. In other words, 53.33\% of manufacturers lacked competitive advantages in TEC. Among these, pure technical efficiency is especially unsatisfactory; only ChipMOS showed improvement in this area. In scale efficiency, $40 \%$ of the companies were close to the optimal productive scale; $46.67 \%$ of the companies had competitive advantages in technique change, in other words, $53.33 \%$ of the companies did not have competitive advantages. Therefore, STSP companies should focus on technical efficiency (especially pure technical efficiency) and technique changes as primary adjustments to strengthen future development of the domestic optoelectronics industry, allowing it to have a greater international competitive advantage.

\section{Bootstrap}

Applications of the Bootstrap procedure resulted in significant differences from the original MPI analysis. Among these, in terms of total factor productivity change, the analysis revealed growth for 50-66.67\% of the companies that showed growth before (Optimax, Chimei Innolux, Coretronic, and ChipMOS) and found a deterioration among 44.44-55.56\% of the companies that showed deterioration before (Formosa Epitaxy, Genesis Photonics, Contrel, MIC, and UTechzone). Regarding technique change, the analysis reveals growth in $42.86-57.14 \%$ of the original companies (HannsTouch, CHIMEI INNOLUX, HannStar, and Coretronic) and deterioration in $37.50 \%$ of the original companies (Genesis Photonics, Contrel, and UTechzone). In TEC, there were no significant changes among the companies. In PTEC, the results showed growth in ChipMOS, which exhibited improvement both in the MPI and Bootstrap analyses; no company with significant deterioration was found. In scale efficiency change, no company had significant growth. HannsTouch Solution had significant deterioration, amounting to $20 \%$ of results in the original analysis. Based on the above, STSP optoelectronics industry manufacturers show equal amounts of advantages and disadvantages in total factor productivity performance. Therefore, these manufacturers should focus on production technology as a primary adjustment direction and achieve significant sustainable growth in productive efficiency to improve the future development of the domestic optoelectronics industry.

\section{Funding}

This study is a project plan funded by the National Science Council and the project number is NSC 97-2410-H-309-010. We are grateful for this support. 


\section{References}

Akanksha, G.; Sanjiv, M. 2010. Measuring retail productivity of food \& grocery retail outlets using the DEA technique, Journal of Strategic Marketing 18(4): 277-289. http://dx.doi.org/10.1080/09652540903537055

Assaf, A.; Matawie, K. M. 2010. Improving the accuracy of DEA efficiency analysis: a bootstrap application to the health care foodservice industry, Applied Economics 42(27): 3547-3558. http://dx.doi.org/10.1080/00036840802112497

Banker, R. D.; Charnes, A.; Cooper, W. W. 1984. Some models for estimating technical and scale inefficiencies in data envelopment analysis, Management Science 30(9): 1078-1092. http://dx.doi.org/10.1287/mnsc.30.9.1078

Bowlin, W. F. 1998. Measuring performance: an introduction to data envelopment analysis (DEA), Journal of Cost Analysis 7: 3-27. http://dx.doi.org/10.1080/08823871.1998.10462318

Caves, D. W.; Christensen, L. R.; Diewert, W. E. 1982. The economic theory of index numbers of the measurement of input, output and productivity, Econometrica 50(6): 1393-1414. http://dx.doi.org/10.2307/1913388

Chang, S. Y.; Chen, T. H. 2008. Performance ranking of Asian lead frame firms: a slack-based method in data envelopment analysis, International Journal of Production Research 46(14): 3875-3885. http://dx.doi.org/10.1080/00207540701197044

Charnes, A.; Cooper, W. W.; Rhodes, E. 1978. Measuring the efficiency of decision making units, European Journal of Operational Research 2(6): 429-444. http://dx.doi.org/10.1016/0377-2217(78)90138-8

Chen, Y. 2003. A non-radial Malmquist productivity index with an illustrative application to Chinese major industries, International Journal Production Economies 83(1): 27-35. http://dx.doi.org/10.1016/S0925-5273(02)00267-0

Dyson, R. G.; Allen, R.; Camanho, A. S.; Podinovski, V. V.; Sarrico, C. S.; Shale, E. A. 2001. Pitfalls and protocols in DEA, European Journal of Operational Research 132: 245-259. http://dx.doi.org/10.1016/S0377-2217(00)00149-1

Efron, B. 1979. Bootstrap methods: another look at the jackknife, Annals of Statistics 7: 1-26. http://dx.doi.org/10.1214/aos/1176344552

Efron, B.; Tibshirani, R. J. 1993. An introduction to the Bootstrap. London: Chapman and Hall. http://dx.doi.org/10.1007/978-1-4899-4541-9

Färe, R.; Grosskopf, S.; Norris, M.; Zhang, Z. 1994. Productivity growth, technical progress, and efficiency change in industrialized countries, The American Economic Review 84(1): 66-83.

Farrell, M. J. 1957. The measurement of productive efficiency, Journal of the royal statistical society 120(3): 253-290. http://dx.doi.org/10.2307/2343100

Fukuyama, H.; Mirdehghan, S. M. 2012. Identifying the efficiency status in network DEA, European Journal of Operational Research 220(1): 85-92. http://dx.doi.org/10.1016/j.ejor.2012.01.024

Golany, B.; Roll, Y. 1989. An application procedure for DEA, Omega 17(3): 237-250. http://dx.doi.org/10.1016/0305-0483(89)90029-7

Kong, W. H.; Fu, T. T. 2012. Assessing the performance of business colleges in Taiwan using data envelopment analysis and student based value-added performance indicators, Omega 40(5): 541-549. http://dx.doi.org/10.1016/j.omega.2011.10.004

Lu, W. M.; Hung, S. W. 2011. Exploring the efficiency and effectiveness in global e-retailing companies, Computers \& Operations Research 38(9): 1351-1360. http://dx.doi.org/10.1016/j.cor.2010.12.009

Malmquist, S. 1953. Index numbers and indifference surfaces, Trabajos de Estadística 4: 209-242. http://dx.doi.org/10.1007/BF03006863

Niven, P. R. 2002. Balanced scorecard step-by-step. New York: Wiley. 
Norman, M.; Stoker, B. 1991. Data envelopment analysis: the assessment of performance. New York: John Wiley and Sons.

Paradi, J. C.; Zhu, H. 2013. A survey on bank branch efficiency and performance research with data envelopment analysis, Omega 41(3): 61-79. http://dx.doi.org/10.1016/j.omega.2011.08.010

Pastor, J. T.; Lovell, C. A. K. 2005. A global Malmquist productivity index, Economics Letters 88(2): 266-271. http://dx.doi.org/10.1016/j.econlet.2005.02.013

Shephard, R. W. 1970. Theory of cost and production functions. Princeton: Princeton University Press.

Shestalova, V. 2003. Sequential Malmquist indices of productivity growth: an application to OECD industrial activities, Journal of Productivity Analysis 19(2): 211-226.

http://dx.doi.org/10.1023/A:1022857501478

Simar, L.; Wilson, P. W. 1999. Estimating and bootstrapping Malmquist indices, European Journal of Operational Research 115: 459-471. http://dx.doi.org/10.1016/S0377-2217(97)00450-5

Sun, S. 2002. Assessing computer numerical control machines using data envelopment analysis, International Journal of Production Research 40(9): 2011-2039. http://dx.doi.org/10.1080/00207540210123634

Toloo, M.; Sohrabi, B.; Nalchigar, S. 2009. A new method for ranking discovered rules from data mining by DEA, Expert Systems with Applications 36: 8503-8508. http://dx.doi.org/10.1016/j.eswa.2008.10.038

Tommaso, A. 2011. Performances and spending efficiency in higher education: a European comparison through non-parametric approaches, Education Economics 19(2): 199-224. http://dx.doi.org/10.1080/09645290903094174

Vaidogas, E. R.; Juocevicius, V. 2007. Assessing external threats to structures using limited statistical data: an approach based on data resampling, Technological and Economic Development of Economy 13(2): 170-175.

Wilson, A. B.; Kerr, B.; Bastian, N. D.; Fulton, L. V. 2012. Financial performance monitoring of the technical efficiency of critical access hospitals: a data envelopment analysis and logistic regression modeling approach, Journal of Healthcare Management 57(3): 200-212.

Chun-Chu LIU. PhD, Professor at the Department of International Business and Director of Executive Master of Business Administration, Chang Jung Christian University, Taiwan.

Author of about 70 scientific articles and 23 projects. Research interests: performance management, multiple criteria decision making, innovation management, and financial institutions management.

An-Chin CHENG. PhD, Assist Professor at the Graduate Institute of Business Administration, Chaoyang University of Technology, Taiwan.

His current research interests include management of technology, technology diffusion and forecasting, decision making, sustainable development and new product management. He has published papers in Technovation, Technological and Economic Development of Economy, Technological Forecasting and Social Change, Romanian Journal of Economic Forecasting, and other journals.

Shih-Hui CHEN. PhD student at the Graduate School of Business and Operations Management, Chang Jung Christian University, Taiwan. Research interests: performance management, multiple criteria decision making, and innovation management. 